\title{
A alteração extrajudicial de prenome e gênero de pessoa transgênero à luz da dignidade humana
}

\author{
The amendment of prenome and gender of the transgender person in the light of \\ human dignity
}

\author{
Francisco Luciano Lima Rodrigues*
}

\section{Resumo}

Este estudo analisa o direito à alteração de prenome e gênero de pessoa transgênero à luz do princípio constitucional da dignidade humana. Verifica, por meio de teorias sociológicas e antropológicas, como a questão de gênero pode ser compreendida a partir de uma construção cultural e social. Apresenta diferentes visões e conceitos sobre a questão de gênero e qual o seu significado para o indivíduo e a comunidade. Aborda a evolução doutrinária e jurisprudencial da alteração de prenome e gênero, verificando as teorias e as decisões de tribunais superiores sobre a referida temática, de forma crítica e construtiva. Trata ainda a respeito da crescente tendência de promover, no âmbito extrajudicial dos cartórios, o acesso à justiça, permitindo que situações concretas sejam solucionadas sem a necessidade acionar o Poder Judiciário. Por fim, analisa o Provimento n. ${ }^{0} 73 / 2018$ do Conselho Nacional de Justiça, que dispôs sobre o procedimento de averbação da alteração do prenome e do gênero de pessoa transgênero, a ser realizado no âmbito das serventias extrajudiciais.

Palavras-chave: Pessoa transgênero. Prenome e gênero. Dignidade humana.

\section{Abstract}

It analyzes the right to change the first name and gender of a transgender person in the light of the constitutional principle of human dignity. It verifies through sociological and anthropological theories how the gender issue can be understood as a cultural and social construct. It presents different visions and concepts, about the gender issue and what its meaning to the individual and the community. It discusses the doctrinal and jurisprudential evolution of the alteration of first name and gender, verifying theories and decisions of higher courts that deal with this topic, in a critical and constructive way. It deals with the growing tendency to promote access to justice in the extrajudicial context of the notary offices, allowing concrete situations to be solved without the need for the judiciary. Finally, he studies Provimento $N^{\circ} 73 / 2018$ of the National Council of Justice, which laid down the procedure for the endorsement of the amendment of the first name and gender of transgender person, to be carried out in the context of extrajudicial service roads.

Keywords: Transgender person. Prenome and genre. Human dignity.

\section{Introdução}

A ciência jurídica moderna vem paulatinamente reconhecendo a necessidade de serem efetivados materialmente os direitos fundamentais e da personalidade de pessoas transgênero, com fundamento no princípio da dignidade da pessoa humana.

Durante muito tempo, a sociedade brasileira foi influenciada por uma cultura preconceituosa, incorrendo na construção de uma visão distorcida acerca da questão de gênero. Contudo, no contexto atual, tem sido possível se verificar uma mudança de visão sobre o tema com o surgimento de políticas e regulamentos que reconhecem e protegem outras formas da percepção de gênero.

A necessidade da discussão permanente acerca da questão de gênero e sua ocorrência no Brasil foi o que suscitou inquietação e levou à realização desta pesquisa. A experiência acadêmica e funcional no

Doutor em Direito pela Universidade Federal de Pernambuco. Mestre em Direito pela Universidade Federal do Ceará. Professor do Programa de Pós-Graduação Stricto Sensu da Universidade de Fortaleza. Desembargador do Tribunal de Justiça do Estado do Ceará. Fortaleza- CE - Brasil. E-mail: lucianolima@unifor.br. 
campo das serventias extrajudiciais fez despertar o interesse em abordar essa temática no aspecto jurídico, de forma a contribuir com estudos de interesse coletivo. Portanto, o presente trabalho pretende analisar o direito à alteração extrajudicial de prenome e gênero à luz da dignidade da pessoa humana.

Em seguida, será verificado o Provimento n. ${ }^{\circ} 73$, de 28 de junho de 2018, do Conselho Nacional de Justiça, que aborda o procedimento de averbação da alteração do prenome e do gênero nos assentos de nascimento e casamento de pessoa transgênero, a ser realizado nas serventias extrajudiciais.

O provimento acima citado teve o seu texto construído em consonância com o Pacto de San José da Costa Rica, que aborda o respeito ao direito ao nome, ao reconhecimento da personalidade jurídica, à liberdade pessoal, à honra e à dignidade.

Esse pacto se apresenta em consonância com a ideia prevalecente na atual hermenêutica do direito privado que defende a interpretação das normas de direito civil a partir da Constituição Federal, tendo como vetor o princípio da dignidade da pessoa, contrapondo-se ao viés patrimonialista que marcou as codificações oitocentistas.

Para a elaboração deste estudo, o enfoque principal será teórico-científico, essencialmente bibliográfico, a partir da doutrina especializada e da legislação que trata sobre o assunto.

Serão abordadas no trabalho questões relativas à concepção de sujeito, de identidade e de gênero, em diálogo com autores como Beauvoir (1980), Butler (2003) e Touraine (2006), e também serão analisados o princípio constitucional da dignidade da pessoa e a posição dos tribunais superiores acerca da alteração de prenome e gênero das pessoas transgênero.

Assim, será adotada a pesquisa bibliográfica, em que, primeiramente, será feito um levantamento de fontes impressas e digitais, para posterior seleção dos conteúdos pertinentes, com intuito de embasar e analisar os dados referentes à pesquisa. $E$, ainda, será procedida uma análise das normas jurídicas que envolvem o tema, buscando-se uma conexão com a realidade social, econômica e política.

A relevância da escolha desse método para o presente estudo baseia-se na premissa de que a pesquisa bibliográfica é um movimento metódico, articulado com a construção dos conceitos essenciais de seu referencial teórico. Ela se desenvolve pelo lento processo de reunir, selecionar e organizar (mental e concretamente) os conceitos e citações a serem utilizados na pesquisa.

Por outro aspecto, na pesquisa bibliográfica adota-se uma postura crítica e construtiva em relação ao conteúdo analisado para melhor fundamentar a abordagem do tema.

A importância da pesquisa bibliográfica como metodologia para o desenvolvimento do trabalho científico está relacionada ao fato de que os ensinamentos delineados em materiais bibliográficos refletem experiências e vivências anteriores, que servem de suporte para a construção do conhecimento.

\section{0 gênero como construção cultural e social}

É um fato que se vive em uma sociedade regida por regras, costumes e tabus e que, muitas das vezes, os indivíduos, enquanto sujeitos, bem como a sua identidade, acabam sendo menoscabados em razão de supostos interesses sociais que são frutos de discursos não reveladores dos seus verdadeiros objetivos.

Essas tais regras fazem com que haja uma naturalidade com relação aos papéis atribuídos ou impostos aos sujeitos a partir do sexo que ostentam. De forma a fugir desse sentido natural, Borrillo e Barboza (2016, p. 04) nos levam à reflexão de que é necessário um trabalho crítico permanente, uma vigilância constante para evitar que se caia na armadilha das evidências e, para isto, afirma a necessidade de que se deixe de lado as lentes com que habitualmente se vê a realidade.

Pode-se complementar o pensamento de Borrillo e Barboza (2016) afirmando que são os valores construídos pela sociedade, dentro daquilo que lhe parece indispensáveis à manutenção do status quo, que constituem as lentes pelas quais podem ser vistos os papéis atribuídos a cada individuo, fazendo parecer normal ou natural aquele entendido como superior e o outro aceito como submisso ou de menor importância. 
A respeito do indivíduo no contexto social, é relevante a abordagem de Touraine (2006, p. 119), que sobre o tema afirma:

A decomposição dos quadros sociais faz triunfar o indivíduo, dessocializado mas capaz de combater tanto a ordem social dominante quanto as forças da morte. $\mathrm{O}$ indivíduo fragmentou-se rapidamente em múltiplas realidades. Um de seus fragmentos nos revelou um eu fragilizado, mutante, submisso a todas as possibilidades, a todas as propagandas e às imagens das culturas de massa. $O$ indivíduo não passa então de uma tela sobre a qual se projetam desejos, necessidades, mundos imaginários fabricados pelas novas indústrias da comunicação. Esta imagem do indivíduo, que já não é mais definido por grupos de pertença, que é cada vez mais enfraquecido e que não encontra mais a garantia de sua identidade em si mesmo, pois já não é mais um princípio de unidade e é obscuramente dirigido por aquilo que escapa à sua consciência, serviu muitas vezes para definir a modernidade.

Pode-se observar que o pensamento crítico acima transcrito nos conduz à noção de que a fragmentação do indivíduo no seio social demonstrou que existe um "eu fragilizado", que é absolutamente subserviente ao bombardeio e à influência de propagandas e de imagens produzidas pela cultura de massa.

A influência desses fatores produzidos pela cultura de massa acaba por reduzir o sujeito, enfraquecendo-o de tal maneira que o faz perder a noção de sua identidade em si mesmo, regendo-se pelo seu plano subconsciente, em vez de pautar-se pela consciência.

Quanto ao sujeito, Touraine (2006, p. 119) destaca:

O sujeito se forma na vontade de escapar às forças, às regras, aos poderes que nos impedem de sermos nós mesmos, que procuram reduzir-nos ao estado de componente de seu sistema e de seu controle sobre a atividade, as intenções e as interações de todos. Estas lutas contra o que nos rouba o sentido de nossa existência são sempre lutas desiguais contra um poder, contra uma ordem. Não há sujeito senão rebelde, dividido entre raiva e esperança.

O sujeito homem quase sempre foi visto como um ser totalmente independente, completo e suficiente por si só, enquanto ao sujeito mulher era reservada uma posição diametralmente oposta, marcado pela dependência e pela incompletude, sendo considerada apenas como um ser relacionado ao sexo. Pode-se afirmar que, na sociedade contemporânea, ainda existem resquícios que apontam para o homem como sendo o sujeito, o absoluto, sendo reservado à mulher a mera função de ser o outro (BEAUVOIR, 1980).

A explicação e a razão pela qual se deu a dominação do homem sobre a mulher é incerta e obscura. No entanto a história e a etnografia tem demonstrado que, se duas categorias humanas se encontram, haverá uma forte tendência de que uma delas queira se sobrepor à outra utilizando como meio a opressão atribuída a causas várias, mas todas desprovidas de qualquer base lógica ou racional que as justifique.

A propósito, ensina Beauvoir (1980, p. 81) que:

O MUNDO sempre pertenceu aos machos. Nenhuma das razões que nos propuseram para explicá-lo nos pareceu suficiente. É revendo à luz da filosofia existencial os dados da pré-história e da etnografia que poderemos compreender como a hierarquia dos sexos se estabeleceu. Já verificamos que, quando duas categorias humanas se acham em presença, cada uma delas quer impor à outra sua soberania; quando ambas estão em estado de sustentar a reivindicação, cria-se entre elas, seja na hostilidade, seja na amizade, sempre na tensão, uma relação de reciprocidade. Se uma das duas é privilegiada, ela domina a outra e tudo faz para mantê-la na opressão. Compreende-se, pois, que o homem tenha tido vontade de dominar a mulher. Mas que privilégio Ihe permitiu satisfazer essa vontade?

Butler (2003), por sua vez, analisa a questão dos "sujeitos" como algo essencial para a política, levando em conta que são produzidos por meio de atos de exclusão. Contudo tais atos não são de fácil percepção, sendo respaldados pela própria estrutura jurídica da política, com o escopo de construir paradigmas de legitimação e de exclusão.

A respeito desse contexto, se posicionou Butler (2003, p. 11):

É minha sugestão que as supostas universalidade e unidade do sujeito do feminismo são de fato minadas pelas restrições do discurso representacional em que funcionam. Com efeito, a insistência prematura [início da página 22] num sujeito estável do feminismo, compreendido como uma categoria 
una das mulheres, gera, inevitavelmente, múltiplas recusas a aceitar essa categoria. Esses domínios de exclusão revelam as consequências coercitivas e reguladoras dessa construção, mesmo quando a construção é elaborada com propósitos emancipatórios. Não há dúvida, a fragmentação no interior do feminismo e a oposição paradoxal ao feminismo por parte de "mulheres" que o feminismo afirma representar - sugerem os limites necessários da política da identidade. A sugestão de que o feminismo pode buscar representação mais ampla para um sujeito que ele próprio constrói gera a consequência irônica de que os objetivos feministas correm o risco de fracassar, justamente em função de sua recusa a levar em conta os poderes constitutivos de suas próprias reivindicações representacionais. Fazer apelos à categoria das mulheres, em nome de propósitos meramente "estratégicos", não resolve nada, pois as estratégias sempre têm significados que extrapolam os propósitos a que se destinam. Nesse caso, a própria exclusão pode restringir como tal um significado inintencional, mas que tem conseqüências. Por sua conformação às exigências da política representacional de que o feminismo articule um sujeito estável, o feminismo abre assim a guarda a acusações de deturpação cabal da representação.

Pode-se ver, assim, que a autora expõe a ideia de que o próprio discurso sobre a questão de gênero e sexo seja o causador de uma preconcepção sobre as temáticas relacionadas, razão pela qual propõe uma ruptura ou quebra dos paradigmas que são estabelecidos aos campos do gênero e sexo por meio do discurso, partindo da premissa de que, sendo o gênero uma construção cultural e social, seria perfeitamente possível que possa ter configurações variadas e distintas.

\section{A alteração de prenome e gênero de pessoa trangênero conforme o princípio da dignidade da pessoa humana}

No palco da natureza, a espécie humana está bem longe de ser a mais forte fisicamente, todavia o cérebro humano possibilitou que o instinto e a razão trabalhassem em parceria para que se concretizassem perguntas e análises do meio ambiente, em prol da sobrevivência (MLODINOW, 2015).

Outra característica que possibilitou a sobrevivência e evolução humana foi a capacidade de associação, o que se deu primeiramente em bandos e depois em comunidades. Nesse sentido, Chauí (2002, p. 464), ao abordar a filosofia aristotélica, expôs que os seres humanos são animais políticos e sociais:

\footnotetext{
O homem é um animal político ou naturalmente político porque é um ser carente e imperfeito que necessita de coisas (para desejar) e de outros (para se reunir), buscando a comunidade como o lugar em que, com os seus semelhantes, alcance a completude. Se fosse sem carências, seria um deus e não precisaria da vida comunitária; se fosse uma besta selvagem nem sequer sentiria a falta de outros. Por não ser um deus nem uma besta feroz, o homem é um animal político.
}

Seguindo essa concatenação lógica de ideias, o fato de o homem conviver em sociedade, seja por vontade própria, seja por uma força natural que o impulsiona, culminou com a necessidade de buscar formas de lutar por direitos, sem que fosse por meio da violência ou com a exigência de sacrifícios desmedidos.

Foi dentro desse contexto que as pessoas, por meio de um pacto social, abdicaram de parcela de sua liberdade e delegaram poder ao Estado, na qualidade de ente maior, dotado de força e capacidade para dirimir os conflitos que Ihe são apresentados, resguardando a harmonia social.

A história mostrou ao homem, especialmente depois da Segunda Guerra Mundial, por conta das atrocidades por ela causadas, a importância da prevalência da pessoa como centro de interesse jurídico, surgindo a necessidade de garantia da sua dignidade, tornando-se, assim, um princípio meta constitucional.

Dessa forma, mostra-se indispensável a abordagem do princípio da dignidade da pessoa humana para o tratamento do tema deste artigo, uma vez que a necessidade de tratar da questão da alteração do prenome e do gênero da pessoa transgênero fortalece a opção do constituinte brasileiro por tal princípio, como indicador de uma unidade axiológica e legitimador da ordem jurídica nacional, incluindo os direitos fundamentais.

A construção do conceito de dignidade da pessoa humana como se tem na atualidade, afirma Barretto (2013, p. 69-70), deve-se a vários autores que estabeleceram o alicerce de uma teoria da dignidade da 
pessoa humana. Essa contribuição perpassa diversas fases da história da humanidade, desde o período romano, quando ter dignidade estava relacionado a sua colocação na sociedade, ultrapassa a idade média com Tomás de Aquino, cuja ideia de dignidade do homem advém da dignidade de Deus, e evolui com o pensamento de Picco Della Mirandola, colocado na obra Discurso sobre a Dignidade Humana, cuja contribuição estaria, como afirma $\operatorname{Moraes}(2010$, p. 116), no fato de ter feito em sua obra diversas alusões a ratio theologica, a par da ratio philosophica, sem, no entanto, estabelecer uma relação, comum à época, entre criador e criatura, aspecto que marcava a evolução do conceito de dignidade de um patamar divino para colocá-la numa direção antropocêntrica.

A Idade Moderna, com o lluminismo, trouxe considerável contribuição à consolidação do conceito de dignidade da pessoa humana a partir das ideias do filósofo Immanuel Kant, que teria, nas palavras de Barcellos (2008, p.124), definido ser o homem um fim em si mesmo - e não uma função do Estado, da sociedade ou da nação - dispondo de uma dignidade ontológica. O direito e o Estado, afirma Barcellos, ao contrário do que se imagina, é que deverão estar organizados em benefício da pessoa, sendo fundamental a separação de poderes e a difusão da legalidade como forma de assegurar aos homens a liberdade de perseguirem seus objetivos individuais.

A obra de Kant trouxe uma nova perspectiva a respeito da questão da moralidade, que pode ser resumida no imperativo categórico traduzido pela sentença: "Age de tal modo que a máxima de tua vontade possa sempre valer simultaneamente como um princípio para uma legislação geral". A propósito, assevera Barroso (2013, p. 70) que:

o imperativo categórico corresponde a uma ação que é boa em si mesma, independentemente do fato de servir a determinado fim. Ele é um padrão de racionalidade e representa o que é objetivamente necessário em uma vontade que esteja em conformidade com a razão. Esse imperativo categórico, ou imperativo de moralidade, foi enunciado por Kant em uma famosa proposição sintética: "Age de tal modo que a máxima da tua vontade (i.e,. o princípio que inspira e move) possa se transformar em uma lei universal". Note-se que em lugar de apresentar um catálogo de virtudes, uma lista do que fazer e do não fazer, Kant concebeu uma fórmula capaz se determinar a ação ética.

O imperativo categórico impõe um comportamento pelo qual o ser humano não possa ser visto como um meio, mas sempre como um fim. A pessoa é o centro das atenções, o ponto de convergência de tudo. Do imperativo, resulta o reconhecimento da dignidade, que, como regra, deve ter como referência: o importante é o respeito à singularidade do outro.

Nesse contexto, merecem referência os ensinamentos de Arendt (2009, p. 188-190):

A pluralidade humana, condição básica da ação e do discurso, tem o duplo aspecto e igualdade e diferença. Se não fossem iguais, os homens seriam incapazes de compreender-se e aos seus ancestrais, ou de fazer planos para o futuro e prever as necessidades das gerações vindouras. Se não fossem diferentes, se cada ser humano não deferisse de todos os que existiram, existem ou vierem a existir, os homens não precisariam do discurso ou da ação para se fazerem entender. Com simples sinais e sons, poderiam comunicar-se imediatas e idênticas.

Ser diferente não equivale a ser outro - ou seja, não equivale a possuir essa curiosa qualidade de "alteridade", comum a tudo o que existe e que, para a filosofia medieval, é uma das quatro características básicas e universais que transcendem todas as qualidades particulares. A alteridade é, sem dúvida, aspecto importante da pluralidade; é a razão pela qual todas as nossas definições são distinções e o motivo pelo qual não podemos dizer o que é uma coisa sem distingui-la de outra [...].No homem, a alteridade, que ele tem em comum com tudo que existe, e a distinção, que ele partilha com tudo o que vive, tornam-se singularidade e a pluralidade humana é a paradoxal pluralidade de seres singulares.

Essa perspectiva de que o homem dentro da sua pluralidade é singular, no sentido de que deve ser o fim, e não o meio, conduz ao entendimento de que ele não pode ser utilizado como instrumento para projetos pessoais de outro, mas que o Estado é que deve servir à pessoa, e não contrário, reafirmando o primado da importância da dignidade como valor intrínseco a cada pessoa.

Apesar da construção conceitual da dignidade da pessoa humana ter avançado consideravelmente desde o período romano até o início do século XX, os horrores da Segunda Guerra Mundial, quando a violação da 
dignidade da pessoa humana chegou ao grau da barbárie, fez surgir reações no plano internacional e nacional, seja pela Declaração Universal dos Direitos Humanos, seja pela adoção do princípio da dignidade da pessoa humana como valor máximo a ser observado na atuação tanto do Estado como dos organismos internacionais.

A inclusão da dignidade da pessoa humana nos textos internacionais e nas constituições, a partir da Segunda Guerra Mundial, consolidou entendimentos a respeito do seu conteúdo, reconhecendo o multiculturalismo, a diversidade das muitas etnias e das sociedades, e estendendo a sua abrangência ao respeito à integridade física, psíquica e corporal da pessoa, admitindo que há necessidades básicas sem as quais estaria violada a dignidade da pessoa humana, dentre elas, a garantia de condições de moradia, saúde básica, educação e trabalho.

Ao lado do atendimento das mencionadas necessidades básicas da pessoa, carece,, para o cumprimento da dignidade da pessoa humana, a adoção de tratamento igualitário e que impeça quaisquer tipos de discriminações, de ordem econômica, étnica, cultural, de opção sexual, religiosa ou política, cujo atendimento favorece a uma igualitária participação política. A igualdade é pressuposto para o atendimento das exigências mínimas do primado da dignidade da pessoa humana, sendo inadmissível para uma existência digna da pessoa o seu tratamento como objeto.

A propósito, afirma Sarlet (2007, p. 118):

O que se percebe, em última análise, é que onde não houver respeito pela vida e pela integridade física do ser humano, onde as condições mínimas para uma existência digna não forem asseguradas, onde a intimidade e identidade do indivíduo forem objeto de ingerências indevidas, onde sua igualdade relativamente aos demais não for garantida, bem como onde não houver limitação de poder, não haverá espaço para a dignidade da pessoa humana, e esta não passará de mero objeto de arbítrio e injustiças. A concepção do homem-objeto, como visto, constitui justamente a antítese da noção da dignidade da pessoa humana.

No Brasil, a Constituição Federal promulgada em 1988 trouxe, como um dos fundamentos da República, juntamente com outros também importantes, o atendimento ao princípio da dignidade da pessoa humana. Pode-se defender, como afirma Silva (2005, p. 38), que o constituinte, ao reconhecer a existência da dignidade da pessoa humana, transformou-a no valor supremo da ordem jurídica e, dessa maneira, sendo um valor fundante da República, deixa de ser apenas um princípio de ordem jurídica para ostentar a qualidade de princípio na ordem política, social, econômica e cultural, trazendo para si todos os direitos fundamentais do homem, desde o direito à vida.

É reconhecida a influência que a Constituição Portuguesa de 1975 exerceu sobre a Constituição brasileira, ambas guardando a semelhança de reservarem à dignidade da pessoa humana o papel de valor fundante da República. A propósito da importância da dignidade da pessoa humana, Canotilho (2003, p. 225) defende que tal princípio tem o papel de, frente às experiências de aniquilamento do ser humano (inquisição, escravatura, stalinismo, nazismo, dentre outros), servir como reconhecimento do homo noumenon, ou seja, do indivíduo como limite e fundamento do domínio político da República, entendida como uma instituição que serve ao homem e não o contrário. Exprimiria, continua Canotilho (2003, p. 225), a dignidade da pessoa humana a ideia de comunidade constitucional inclusiva, pautada pelo multiculturalismo mundividencial, religioso ou filosófico e, dessa forma, a República portuguesa somente poderia conceber-se como ordem livre na medida em que não se identificasse com qualquer "tese", "dogma", "religião" ou "verdade" de compreensão da vida e do mundo.

$\mathrm{Na}$ ordem jurídica brasileira, a partir da atual Constituição, a dignidade da pessoa humana passou a ser o fundamento do sistema, servindo de base, parâmetro e limite de todo ele, ostentando uma superior fundamentalidade com relação aos demais princípios, sem que com isto coloque em descrédito a ausência de hierarquia entre os princípios e a sua superioridade frente às regras.

O lugar destinado para a dignidade da pessoa humana na nova ordem constitucional, em que a pessoa é o centro das atenções, influenciou a interpretação das normas de direito privado, especialmente as de direito civil. Nessa circunstância, passou-se a considerar de importante realce o estudo dos direitos fundamentais e a sua intersecção com as relações particulares. 
Com relação a esse fato, afirma Queiroz (2002, p. 272-273) que na constitucionalização do direito privado se observa, a partir da identificação dos direitos e liberdades fundamentais como princípios inarredáveis e supremos da ordem constitucional, sob o qual ficam abrigados de qualquer relativização, um fato que conduz à percepção de uma relação entre o direito constitucional e o direito privado. Mais adiante, a citada autora defende que:

A esta relação não é estranha a afirmação do "primado" ou "supremacia" da Constituição (Vorrang der Verfassung). Na concepção "clássica" dos direitos estes vinham essencialmente caracterizados como "direitos de defesa", orientados contra o poder executivo e, particularmente, contra a Administração Pública. A esta luz, o direito constitucional não podia assumir uma função protectora ou garantidora dos direitos face ao direito privado que apareceria então como o "baluarte" autêntico da liberdade individual.

Por essa época, o direito privado regulava as relações dos particulares do ponto de vista da liberdade individual à margem das relações políticas e constitucionais. Daí a posição secundaria do direito constitucional face ao direito privado, definido este último como o direito constitutivo da sociedade burguesa. Mais, segundo GRIMM nessa construção, o direito privado deteria mesmo uma "primazia material" sobre o direito constitucional. O direito privado vinha então concebido e interpretado como um direito à margem e independente do Estado.

Como sistema delimitativo de esferas de liberdades, o direito privado assumiu, parcialmente, o papel dos direitos fundamentais. Neste contexto, a liberdade foi expressamente estendida às relações laborais e às relações de emprego público. É a partir dessa época que o legislador passa a estar vinculado pelos direitos fundamentais, nestes incluídos os institutos de direito privado garantidos pela Constituição. É em Weimar que esse movimento de "constitucionalização" do "direito privado" emerge pela primeira vez, com contundência e vigor.

A adoção do princípio da dignidade da pessoa humana pela Constituição Federal brasileira também influenciou o processo de constitucionalização do direito civil, na medida em que, além da mudança de parâmetro de interpretação do Código Civil, que passou a ter por referência a Constituição, tornou-se indispensável a preservação da dignidade da pessoa humana nas relações interpessoais, comportamento compatível com a relocação da pessoa no centro do sistema jurídico em substituição da coisa.

Numa sociedade desigual como a brasileira, conservadora e patrimonialista, com uma indisfarçável dificuldade para reconhecer as diferenças sociais e combatê-las, o princípio da dignidade da pessoa humana é instrumento eficaz para que se impeça a coisificação do homem.

Assim, a importância da dignidade da pessoa humana como um valor fundamental da república também se mostra indispensável na garantia da pessoa quanto à afirmação de sua sexualidade, com especial destaque para a hipótese do transgênero, uma vez que, nessa situação, há uma dissonância entre o tipo de genitália e a forma como a pessoa se vê, daí a necessidade de, muitas vezes, alterar o prenome e o gênero no registro civil.

Nesse cenário, a personalidade individualiza a pessoa natural, estando diretamente relacionada com a capacidade que os indivíduos possuem para serem sujeitos de direitos e obrigações em sociedade. Dentre os direitos que fazem parte da personalidade, temos como destaque: a vida, a honra, o nome e a integridade física e moral.

O nome é uma forma de identificar e individualizar o ser humano no seio social, de maneira a distinguilo dos demais membros da família e da sociedade. Em regra, o nome é dado à pessoa em seu nascimento e o acompanha até o fim de sua personalidade, o que se dá com a morte, sendo que, mesmo após o fim da existência terrena, o nome da pessoa permanece sendo lembrado pela família, amigos ou terceiros que tenham tido contato com o falecido ou com as suas obras deixadas (LOUREIRO, 2016).

A maneira como é utilizado o nome no Brasil tem a sua origem histórica advinda da Roma antiga, quando o sistema onomástico romano abrangia quatro elementos: praenomen (prenome); nomen gentilium (nome de família ou sobrenome); cognomen (servia para distinguir os nomes do mesmo clã) e o agnomen (elemento que permite distinguir a pessoa de um ancestral de nome idêntico) (LOUREIRO, 2016).

A aquisição do nome civil pode se dar por ocasião do nascimento, casamento, adoção e em outras situações que estão previstas em lei. Dentro desse contexto, de acordo com o sistema jurídico brasileiro, 
prepondera o princípio da imutabilidade do nome, ou seja, somente em hipóteses específicas poderão ocorrer alterações no nome.

O claro objetivo da imutabilidade do prenome e do nome de família é velar pela segurança nas relações sociais, de forma a manter a estabilidade nos contratos e pactos celebrados, bem como em todos os demais atos da vida civil.

A Lei Federal n. ${ }^{\circ} 6.015 / 73$ trata sobre os registros públicos, sendo que o seu artigo 58 expõe a imutabilidade do prenome como uma regra que excepcionalmente pode ser afastada.

Art. 58. O prenome será definitivo, admitindo-se, todavia, a sua substituição por apelidos públicos notórios.

Parágrafo único. A substituição do prenome será ainda admitida em razão de fundada coação ou ameaça decorrente da colaboração com a apuração de crime, por determinação, em sentença, de juiz competente, ouvido o Ministério Público. (BRASIL, 1973, não paginado).

Dentre as causas ensejadoras de alteração do prenome e sobrenome, merecem destaque: erro gráfico evidente; nome ridículo ou vexatório; homonímia que cause embaraço na vida pública; no caso de vítimas e testemunhas criminais; apelido público e notório que venha a substituir o nome no ambiente em que vive; e na hipótese de adoção.

Todavia, à luz do princípio da dignidade humana, surgiram algumas decisões judiciais que demonstraram sensibilidade às necessidades sociais e psicológicas de pessoas transexuais, de forma a autorizar a alteração de seus nomes após passarem por cirurgia de transgenitalização.

A respeito da possibilidade de alteração do nome após cirurgia de redesignação sexual, afirma a ministra Nancy Andrigui:

[ ] se o estado já consentiu com a possibilidade de realizar-se cirurgia de transgenitalização, logo deve também prover os meios necessários para que o indivíduo tenha uma vida digna e, por conseguinte, seja identificado jurídica e civilmente como tal como se apresenta perante a sociedade. (STJ REsp, 1.008.398/SP, de 15/10/2009).

Nessa linha de pensamento, merece relevo a edição do Decreto n. ${ }^{\circ}$ 8.757, de 28.04.2016, que dispõe sobre o nome social e o reconhecimento da identidade de gênero de pessoas travestis e transexuais no âmbito da administração pública federal direta, autárquica e fundacional.

A partir do mencionado regulamento, tornou-se possível que a pessoa travesti ou transexual, através de requerimento feito a qualquer tempo, faça a inclusão de seu nome social em documentos oficiais e nos registros de sistemas de órgãos públicos.

Vale considerar que, num primeiro momento, somente tinha o direito de alterar o seu nome e a sua identificação civil aqueles transgêneros que se submetessem à cirurgia de redesignação de sexo, ficando os demais submetidos a situações constrangedoras em sua esfera psíquica e social.

O Supremo Tribunal Federal, quando do julgamento da Ação Direta de Inconstitucionalidade (ADI) n. ${ }^{\circ}$ 4.275/DF, conferiu ao art. 58 da Lei n. ${ }^{\circ}$ 6.015/73 interpretação conforme a Constituição Federal, para reconhecer o direito da pessoa, independentemente de cirurgia de redesignação ou da realização de tratamentos hormonais ou patologizantes, promover a substituição de prenome e gênero.

\section{0 procedimento de alteração de prenome e gênero de acordo com o Provimento n. $^{\circ}$ 73/2018 do Conselho Nacional de Justiça}

Tem se mostrado uma tendência cada vez mais crescente a promoção do acesso à justiça no âmbito extrajudicial dos cartórios, tecnicamente denominados de serventias extrajudiciais, permitindo que situações concretas sejam solucionadas sem a necessidade do Poder Judiciário.

Nesse propósito, o Provimento n. ${ }^{\circ} 73$, de 28 de junho de 2018, do Conselho Nacional de Justiça, dispôs sobre o procedimento de averbação da alteração do prenome e do gênero nos assentos de nascimento e 
casamento de pessoa transgênero, a ser realizado no âmbito das serventias extrajudiciais, especificamente na competência do Registro Civil das Pessoas Naturais (BRASIL, 2018).

O referido provimento do Conselho Nacional de Justiça (CNJ) é diretamente fundamentado em legislação internacional, como no Pacto de San José da Costa Rica, que impõe o respeito ao direito ao nome, ao reconhecimento da personalidade jurídica, à liberdade pessoal, à honra e à dignidade.

Ademais, a República Federativa do Brasil é signatária da Convenção Interamericana de Direitos Humanos, que também possui dispositivos que respaldam a alteração do prenome e do gênero nos assentos de nascimento e casamento de pessoa transgênero.

O caput do artigo $4^{\circ}$ do Provimento n. ${ }^{\circ} 73 / 2018$ do Conselho Nacional de Justiça traz que o procedimento será feito de acordo com a autonomia do interessado, que poderá requerer a averbação de alteração do prenome, do gênero ou de ambos. $\mathrm{O} \S 6^{\circ}$ do mesmo dispositivo indica os documentos obrigatórios para o ato.

Art. $4^{\circ} \mathrm{O}$ procedimento será realizado com base na autonomia da pessoa requerente, que deverá declarar, perante o registrador do RCPN, a vontade de proceder à adequação da identidade mediante a averbação do prenome, do gênero ou de ambos.

$\S 1^{\circ} \mathrm{O}$ atendimento do pedido apresentado ao registrador independe de prévia autorização judicial ou da comprovação de realização de cirurgia de redesignação sexual e/ou de tratamento hormonal ou patologizante, assim como de apresentação de laudo médico ou psicológico.

$\S 2^{\circ} \mathrm{O}$ registrador deverá identificar a pessoa requerente mediante coleta, em termo próprio, conforme modelo constante do anexo deste provimento, de sua qualificação e assinatura, além de conferir os documentos pessoais originais.

$\S 3^{\circ} \mathrm{O}$ requerimento será assinado pela pessoa requerente na presença do registrador do RCPN, indicando a alteração pretendida.

$\S 4^{\circ} \mathrm{A}$ pessoa requerente deverá declarar a inexistência de processo judicial que tenha por objeto a alteração pretendida.

$\S 5^{\circ} \mathrm{A}$ opção pela via administrativa na hipótese de tramitação anterior de processo judicial cujo objeto tenha sido a alteração pretendida será condicionada à comprovação de arquivamento do feito judicial.

$\S 6^{\circ} \mathrm{A}$ pessoa requerente deverá apresentar ao ofício do RCPN, no ato do requerimento, os seguintes documentos:

I - certidão de nascimento atualizada;

II - certidão de casamento atualizada, se for o caso;

III - cópia do registro geral de identidade (RG);

IV - cópia da identificação civil nacional (ICN), se for o caso;

$\mathrm{V}$ - cópia do passaporte brasileiro, se for o caso;

VI - cópia do cadastro de pessoa física (CPF) no Ministério da Fazenda;

VII - cópia do título de eleitor;

IX - cópia de carteira de identidade social, se for o caso;

$X$ - comprovante de endereço;

XI - certidão do distribuidor cível do local de residência dos últimos cinco anos (estadual/federal);

XII - certidão do distribuidor criminal do local de residência dos últimos cinco anos (estadual/federal);

XIII - certidão de execução criminal do local de residência dos últimos cinco anos (estadual/federal);

XIV - certidão dos tabelionatos de protestos do local de residência dos últimos cinco anos;

$X V$ - certidão da Justiça Eleitoral do local de residência dos últimos cinco anos;

XVI - certidão da Justiça do Trabalho do local de residência dos últimos cinco anos;

XVII - certidão da Justiça Militar, se for o caso. (BRASIL, 2018, não paginado).

Os documentos obrigatórios acima elencados têm por objetivo garantir a segurança jurídica das relações sociais e comerciais que tenham sido firmadas pela pessoa que passará a ter outro nome e gênero. Nesse compasso, tem-se a harmonização dos princípios da dignidade humana e da segurança jurídica (SARDINHA, 2019). 
$\mathrm{Na}$ hipótese de alguns dos documentos dispostos no $\S 6^{\circ}$ do artigo $4^{\circ}$ do Provimento n. ${ }^{\circ} 73 / 2018$ do Conselho Nacional de Justiça não serem apresentados, restará configurado o impedimento para a concretização do procedimento de alteração de prenome e gênero da pessoa transgênero.

O Direito Notarial e Registral possui princípios aplicáveis às atividades de notas e de registros públicos de natureza pública, com especial destaque para os da legalidade, impessoalidade, moralidade, publicidade e eficiência, que estão indicados no caput do artigo 37 da Constituição Federal (BRASIL, 1988).

O Estatuto dos Notários e Registradores, a Lei Federal n. ${ }^{\circ}$ 8.935, do ano de 1994, dispõe em seu primeiro artigo que: "Serviços notariais e de registro são os de organização técnica e administrativa destinados a garantir a publicidade, autenticidade, segurança e eficácia dos atos jurídicos" (BRASIL, 1994, não paginado).

Diante disso, o princípio da publicidade, que rege Direito Notarial e Registral, significa que os atos praticados pelo notário e registrador, em regra, são públicos. Dessa maneira, qualquer interessado pode requerer certidão, sem a necessidade de informar ou justificar a sua pretensão em relação à informação obtida (SARDINHA, 2019).

Por outro viés, o princípio da publicidade, em regra, tem a sua aplicação direcionada para qualquer serviço eminentemente público. Ao relacioná-lo diretamente com as atividades desenvolvidas pelos notários e registradores, esse princípio objetivará garantir a eficácia dos atos realizados em relação a terceiros e toda a sociedade.

A publicidade tem por finalidade outorgar segurança às relações jurídicas, assegurando a qualquer interessado o conhecimento do teor do acervo das serventias notariais e registrais e garantir sua oponibilidade contra terceiros, o que, no direito brasileiro se dá por meio de expedição de certidão, a chamada publicidade formal ou indireta. (EL DEBS, 2016, p. 1590).

Destaca-se que a publicidade a ser aplicada no âmbito das serventias extrajudiciais é a publicidade indireta, sendo assim, o interessado que vir a necessitar de uma informação não terá acesso diretamente aos livros e arquivos que fazem parte do acervo da serventia extrajudicial, e que, portanto, estão sob a responsabilidade de guarda e conservação do delegatário (LOUREIRO, 2016).

É certo que, por meio da aplicação da publicidade indireta, o acervo físico da serventia extrajudicial permanecerá mais bem conservado, pois se evita o manuseio indevido e inadequado de livros e documentos, que podem acabar sendo deteriorados quando erroneamente utilizados.

Os registradores e notários, via de regra não podem permitir o acesso direto do interessado aos livros, pois haveria risco à conservação desses arquivos, afetando dessa forma, a segurança jurídica almejada pela publicidade, salvo em alguns casos legais, como por exemplo o disposto no Dec. Lei $n^{\circ} 58 / 37$, art. $1^{\circ} \S 5^{\circ}$ (O memorial, o plano de loteamento e os documentos depositados serão franqueados, pelo oficial de registro, ao exame de qualquer interessado, independentemente do pagamento de emolumentos, ainda que a título de busca) e na Lei Federal $n^{\circ} 6.766 / 79$, art. 24 (O processo de loteamento e os contratos de depositados em Cartório poderão ser examinados por qualquer pessoa, a qualquer tempo, independentemente do pagamento de custas ou emolumentos, ainda que a título de busca). (EL DEBS, 2016, p. 1590).

Por certo que a publicidade indireta também colabora com a segurança jurídica dos atos lavrados na serventia extrajudicial, evitando a rasura de documentos ou a alteração indevida de informações. Isto posto, o princípio da publicidade é a regra geral no âmbito notarial e registral, todavia excepcionalmente há a relativização de tal publicidade. Assim, o artigo $5^{\circ}$ do Provimento n. ${ }^{\circ} 73 / 2018$ do Conselho Nacional de Justiça determina que:

Art. $5^{\circ} \mathrm{A}$ alteração de que trata o presente provimento tem natureza sigilosa, razão pela qual a informação a seu respeito não pode constar das certidões dos assentos, salvo por solicitação da pessoa requerente ou por determinação judicial, hipóteses em que a certidão deverá dispor sobre todo o conteúdo registral. (BRASIL, 2018, s.p.).

A manutenção do sigilo quanto às averbações referentes às alterações de nome e gênero, efetivadas nos registros de nascimento ou de casamento de pessoa transgênero, tem o intuito de preservar a intimidade e a dignidade da pessoa, evitando as situações que possam macular a honra objetiva ou subjetiva. 
Questão relevante, que merece ser trazida à tona, diz respeito a eventual situação do delegatário da serventia extrajudicial suspeitar de fraude, falsidade, má fé, vício de vontade ou simulação, no que tange ao desejo real da pessoa que requer a alteração do seu nome e gênero no âmbito extrajudicial do Registro Civil de Pessoas Naturais. Concretizando-se tal situação, o delegatário da serventia extrajudicial deve fundamentar a recusa e encaminhar o procedimento para que o juiz corregedor permanente analise o caso, respeitando os termos do artigo $6^{\circ}$ do Provimento n. ${ }^{\circ} 73 / 2018$ do Conselho Nacional de Justiça, abaixo transcrito: "Art. $6^{\circ}$ Suspeitando de fraude, falsidade, má-fé, vício de vontade ou simulação quanto ao desejo real da pessoa requerente, o registrador do RCPN fundamentará a recusa e encaminhará o pedido ao juiz corregedor permanente" (BRASIL, 2018, s.p.).

Os princípios da segurança jurídica e da legalidade formam a coluna mestra, capaz de sustentar a funcionalidade social do Direito Notarial e Registral, aspecto que impõe ao delegatário de serventia extrajudicial o dever de fiscalizar o cumprimento dos requisitos legais e a preservação da segurança jurídica em relação aos atos que pratica no exercício de seu ofício.

\section{Considerações finais}

Com a edição do Provimento n. ${ }^{\circ} 73 / 2018$, o Conselho Nacional de Justiça buscou o respeito à liberdade individual e a consagração da dignidade da pessoa humana, colaborando com o avanço do processo de aceitação pela sociedade das diferenças entre os indivíduos, com especial destaque para a situação em que há uma dissociação entre a genitália e a forma como a pessoa se vê no âmbito da sua sexualidade.

De acordo com a Constituição Federal brasileira e o Pacto de San José da Costa Rica, faz-se necessário que se acolha a liberdade da pessoa transgênero de modificar o seu prenome e sexo, nos assentos de nascimento e casamento, de competência dos Registros Civis de Pessoas Naturais, de forma célere e eficiente, garantindo à pessoa transgênero o direito de ser adequadamente tratada como ser individual e social.

É necessário que se modifiquem as lentes pelas quais se costuma catalogar as pessoas a partir de critérios relativos ao gênero para que diferenças individuais possam ser aceitas e respeitadas pela sociedade, de forma a evitar a proliferação de comportamentos preconceituosos, garantindo o respeito às características sexuais de cada indivíduo.

Cabe ao Estado, também por meio dos serviços notariais, fundamentado no princípio da dignidade da pessoa humana e dos tratados internacionais, garantir a adequação do prenome e do sexo das pessoas transgênero às suas reais condições psicológicas, no caso, a forma como se vê perante sua sexualidade, permitindo que haja uma correspondência entre a genitália e a forma como o individuo se compreende.

Considerando, portanto, as novas formações familiares, o livre exercício da sexualidade e a percepção que os indivíduos possuem sobre si mesmos, não é mais cabível o impedimento, sem justo motivo, ao exercício do direito de uma pessoa transgênero de alterar o seu prenome e o seu gênero, uma vez que sociedade brasileira é composta por uma heterogeneidade individual e coletiva que merece a proteção do Estado.

\section{Referências}

ARENDT, Hanna. A condição humana. Tradução: Roberto Raposo. 10. ed. Rio de Janeiro: Forense Universitária, 2009.

BARRETTO, Vicente de Paulo. O fetiche dos direitos humanos e outros temas. 2. ed. Porto Alegre: Livraria do Advogado, 2013.

BARROSO, Luis Roberto. Fundamentos teóricos e filosóficos do novo direito constitucional brasileiro. In: BARROSO, Luis Roberto (org.). A nova interpretação constitucional: ponderação, direitos fundamentais e relações privadas. 3. ed. Rio de Janeiro: Renovar, 2008. p. 1-48.

BARROSO, Luis Roberto. A dignidade da pessoa humana no direito constitucional contemporâneo: a construção de um conceito jurídico à luz da jurisprudência mundial. Belo Horizonte: Fórum, 2013. 
BEAUVOIR, Simone de. O segundo sexo. Tradução: Sérgio Milliet. Rio de Janeiro: Nova Fronteira, 1980. BONAVIDES, Paulo. Curso de direito constitucional positivo. 13. ed. São Paulo: Malheiros, 2003.

BRASIL. Conselho Nacional de Justiça. Provimento $n^{\circ} 73$, de 28 de junho de 2018. Dispõe sobre a averbação da alteração do prenome e do gênero nos assentos de nascimento e casamento de pessoa transgênero no Registro Civil das Pessoas Naturais (RCPN). Disponível em: http://www.cnj.jus.br/buscaatos-adm?documento=3503. Acesso em: 22 maio 2019.

BRASIL. [Constituição (1988)]. Constituição da República Federativa do Brasil de 1988. Brasília, DF: Presidência da República, [2019]. Disponível em: http://www.planalto.gov.br/ccivil_03/constituicao/ constituicao.htm. Acesso em: 12 abr. 2019.

BRASIL. Lei $n^{\circ} 6.015$, de 31 de dezembro de 1973. Dispõe sobre os registros públicos, e dá outras providências. Brasília, DF: Presidência da República, [2019]. Disponível em: http://www.planalto.gov.br/ ccivil_03/LEIS/L6015consolidado.htm. Acesso em: 21 maio 2019.

BRASIL. Lei $n^{\circ} 8.757$, de 10 de maio de 2016. Altera o Decreto $n^{\circ} 86.715$, de 10 de dezembro de 1981, para dispor sobre a situação jurídica do estrangeiro na República Federativa do Brasil. Brasília, DF: Presidência da República, [2019]. Disponível em: http://www.planalto.gov.br/ccivil_03/_Ato20152018/2016/Decreto/D8757.htm. Acesso em: 21 maio 2019.

BRASIL. Lei $n^{\circ}$ 8.935, de 18 de novembro de 1994. Regulamenta o art. 236 da Constituição Federal, dispondo sobre serviços notariais e de registro. (Lei dos Cartórios). Brasília, DF: [2019]. Disponível em: http://www.planalto.gov.br/CCivil_03/LEIS/L8935.htm. Acesso em: 21 maio 2019.

BRASIL. Superior Tribunal de Justiça. Recurso Especial no 1008.398 SP. Relatora: Min. Nancy Andrighi. Brasília, DF, 15 de outubro de 2009. Disponível em: https://stj.jusbrasil.com.br/jurisprudencia/5718884/ recurso-especial-resp-1008398-sp-2007-0273360-5. Acesso em: 20 maio 2019.

BORRILLO, Daniel; BARBOZA, Heloisa Helena. Sexo, gênero e direito: considerações à luz do direito francês e brasileiro. Civilistica.com, Rio de Janeiro, ano 5, n. 2, p. 1-16, 2016. Disponível em: http:// civilistica.com/sexo-genero-e-direito/. Data de acesso: 16 mar. 2020.

BUTLER, Judith. Problemas de gênero: feminismo e subversão da identidade. Tradução: Renato Aguiar. Rio de Janeiro: Civilização Brasileira, 2003.

CHAUÍ, Marilena. Introdução à história da filosofia: dos pré socráticos a Aristóteles. São Paulo: Companhia das Letras, 2002. v. 1.

EL DEBS, Martha. Legislação notarial e de registros públicos comentada. 3. ed. São Paulo: Editora Juspodium, 2016.

LOUREIRO, Luiz Guilherme. Registros públicos: teoria e prática. 8. ed. Salvador: Juspodivm, 2016.

MARMELSTEIN, George. Curso de direitos fundamentais. 4. ed. São Paulo: Atlas: 2013.

MLODINOW, Leonard. De primatas a astronautas: a jornada do homem em busca do conhecimento. Tradução: Cláudio Carina. Rio de Janeiro: Zahar, 2015.

MORAES, Maria Celina Bodin de. Na medida da pessoa humana: estudos de direito civil. Rio de Janeiro: Renovar, 2010.

MORAES, Maria Celina Bodin de. O conceito de dignidade humana: substrato axiológico e conteúdo normativo. In: SARLET, Ingo Wolfgang. Constituição, direitos fundamentais e direito privado. 3. ed. Porto Alegre: Livraria do Advogado, 2010. p. 105-147.

QUEIROZ, Cristina M. M. Direitos fundamentais: teoria geral. Coimbra: Editora Coimbra, 2002.

SARDINHA, Cristiano de Lima Vaz. Cartórios e acesso à justiça: a contribuição das serventias extrajudiciais para a sociedade contemporânea, como alternativa ao poder judiciário. 2. ed. Salvador: Juspodium, 2019. 
SARLET, Ingo Wolfgang. A eficácia dos direitos fundamentais. 9. ed. Porto Alegre: Livraria do Advogado, 2007.

TOURAINE, Alain. Um novo paradigma: para compreender o mundo de hoje. Petrópolis: Vozes, 2006.

Recebido em: 16/05/2020

Aprovado em: 16/11/2020 